\title{
Investigation into the Electromechanical Properties of Dielectric Elastomers Subjected to Pre-Stressing
}

\author{
Liang Jiang \\ Technological University Dublin \\ Tony Betts \\ Technological University Dublin, anthony.betts@tudublin.ie \\ David Kennedy \\ Technological University Dublin, david.kennedy@tudublin.ie
}

See next page for additional authors

Follow this and additional works at: https://arrow.tudublin.ie/scschcpsart

\section{Recommended Citation}

Jiang, L., Betts, A. \& Kennedy, D. (2015). Investigation into the Electromechanical Properties of Dielectric Elastomers Subjected to Pre-Stressing, Materials Science and Engineering C, vol. 49, pg.754-760. doi: 10.1097/OPX.0000000000000431 doi:10.1016/j.msec.2015.01.070

This Article is brought to you for free and open access by the School of Chemical and Pharmaceutical Sciences at ARROW@TU Dublin. It has been accepted for inclusion in Articles by an authorized administrator of ARROW@TU Dublin. For more information, please contact arrow.admin@tudublin.ie, aisling.coyne@tudublin.ie, gerard.connolly@tudublin.ie.






\section{Authors}

Liang Jiang, Tony Betts, David Kennedy, and Stephen Jerrams

This article is available at ARROW@TU Dublin: https://arrow.tudublin.ie/scschcpsart/42 


\title{
Investigation into the electromechanical properties of dielectric elastomers subjected to pre-stressing
}

\author{
Liang Jiang a,*, Anthony Betts ${ }^{\mathrm{b}}$, David Kennedy ${ }^{\mathrm{c}}$, Stephen Jerrams ${ }^{\mathrm{a}}$ \\ a Centre for Elastomer Research (CER), Focas Research Institute, Dublin Institute of Technology, Dublin 8, Ireland \\ b The Applied Electrochemistry Group (AEG), Focas Research Institute, Dublin Institute of Technology, Dublin 8, Ireland \\ c Department of Mechanical Engineering, Dublin Institute of Technology, Dublin 1, Ireland
}

\section{A R T I C L E I N F O}

\section{Article history:}

Received 10 March 2014

Received in revised form 2 December 2014

Accepted 22 January 2015

Available online 23 January 2015

Keywords:

Dielectric elastomers

Silicone rubber $/ \mathrm{BaTiO}_{3}$

VHB 4910

Pre-stretch

Pull-in instability

Energy density

\begin{abstract}
A B S T R A C T
Dielectric elastomers (DEs) are being exploited for biological applications such as artificial blood pumps, biomimetic grippers and biomimetic robots. Generally, polyacrylate and silicone rubber (SR) are the most widely used materials for fabricating DEs in terms of mixing with other polymers or compounding them with highly dielectric particles. Furthermore, pre-stretch offers an effective approach to increasing actuated strain and dielectric strength and eliminating 'pull-in' instability. In the work described here, a comparison in electromechanical properties was made between $\mathrm{SR} / 10 \%$ barium titanate $\left(\mathrm{BaTiO}_{3}\right)$ and commercial VHB 4910 . Trends in these dielectric parameters are shown graphically for variation in pre-stretch ratio $\left(\lambda_{\text {pre }}\right)$. It was found that permittivity of $\mathrm{SR} / 10 \% \mathrm{BaTiO}_{3}$ was independent of frequency, whereas permittivity was frequency-independent due to the polarization of polymer chains. The maximum deformation and the coupling efficiency for $\mathrm{SR} / 10 \% \mathrm{BaTiO}_{3}$ can be achieved at a pre-stretch ratio between 1.6 and 1.9. For VHB 4910, they can be obtained in the prestretch ratio range from 2.6 to 3.0. A maximum energy density of $0.05 \mathrm{MJ} / \mathrm{m}^{3}$ was achieved by $\mathrm{SR} / 10 \% \mathrm{BaTiO}_{3}$ $\left(\lambda_{\text {pre }}=1.6\right)$ and VHB $4910\left(\lambda_{\text {pre }}=3.4\right)$. The findings provide an insight into critical pre-stretch ratios required for a range of applications of DEs based on silicone and the commercially available polyacrylate VHB 4910.
\end{abstract}

@ 2015 Elsevier B.V. All rights reserved.

\section{Introduction}

Dielectric elastomers (DEs) are also termed dielectric electroactive polymers which are a subset of electroactive polymers (EAPs). The high dielectric properties of a DE can be used to induce a large actuated strain by the application of an electric field. DEs were discovered by Pelrine [1]. In his experiments, area strains of up to $30 \%$, corresponding to actuation pressures as high as $1.9 \mathrm{MPa}$ and high specific energy densities up to $0.1 \mathrm{~J} / \mathrm{g}$, were obtained. DEs have gained a deserved reputation as "artificial muscles" [2-4] because they behave similarly to biological muscles in terms of actuation pressure, energy conversion efficiency and response speed to stimulus. Hence DEs are used for intelligent applications such as tactile displays [5-7], bionic actuators [8-12] and other applications [13-16].

The working principle of DEs is illustrated in Fig. 1. When a high voltage is applied to the compliant electrodes which are coated onto the surfaces of a DE, the DE can quickly change its shape and when the electric stimulus is removed, the DE rapidly recovers its original shape. The pressure produced by the electrostatic force induced by the electric stimulus compresses the film and transfers electrical energy into mechanical energy $[17,18]$.

\footnotetext{
* Corresponding author.

E-mail address: liang.jiang@mydit.ie (L. Jiang).
}

DEs can be considered as isochoric (volume retaining materials) [4] When a high voltage is applied, the relation between the area strain $\mathrm{s}_{\mathrm{a}}$ and the thickness strain $\mathrm{s}_{\mathrm{z}}$ (the compressive ratio in thickness), can be easily obtained from Eq. (1).

$\left(1+\mathrm{s}_{\mathrm{a}}\right)\left(1-\mathrm{s}_{\mathrm{z}}\right)=1$

The pressure, $\mathrm{p}$ which originates from the Maxwell stress, created between the positive charges on the top surface of the DE and the negative charges on the bottom surface of the DE, complies with Eq. (2) [19]:

$\mathrm{p}=\varepsilon^{\prime} \varepsilon_{0}\left(\frac{\Phi}{\mathrm{H}}\right)^{2}=\varepsilon^{\prime} \varepsilon_{0} \varphi^{2}$

where $\varepsilon^{\prime}$ is the relative permittivity (dielectric constant) of the DE material, $\varepsilon_{0}$ is the permittivity of the free space $\left(8.85 \times 10^{-12} \mathrm{~F} / \mathrm{m}\right), \varphi$ is the electric field which equals the applied high voltage $(\Phi)$ divided by the initial thickness of the $\mathrm{DE}(\mathrm{H})$.

However, for a dielectric elastomer, the voltage-actuated strain is often limited by pull-in instability (electromechanical instability) [20] and electrical breakdown. As the applied voltage is increased, the thickness of the polymer decreases, so that this same applied voltage induces an even higher electric field. In this case, the pull-in instability may 


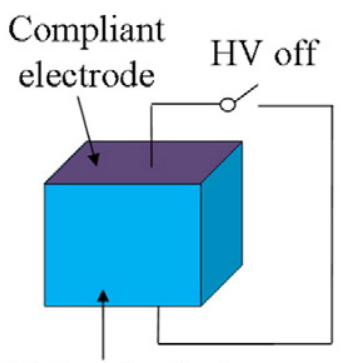

Dielectric elastomer

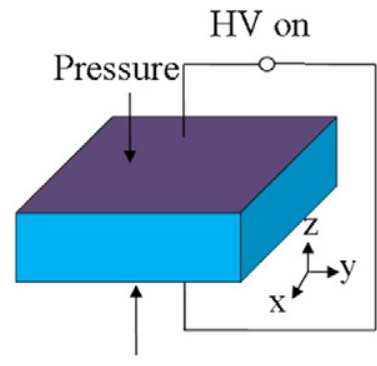

Fig. 1. Schematic representation of a DE's working principle.

cause the DE to reduce in thickness drastically and this can lead to electrical breakdown. Zhao [21] determined conditions for pull-in instability by analyzing voltage-stretch curves $\Phi(\lambda)$ deduced from stress-stretch curves $\sigma(\lambda)$ (Eq. (6)).

$\Phi=\mathrm{H} \lambda^{-2} \sqrt{\sigma(\lambda) / \varepsilon}$

where $\varepsilon \approx \varepsilon^{\prime} \varepsilon_{0}$ is the permittivity of elastomers.

Zhao assumed the material conformed to a neo-Hookean model and the application of the current induces a uniaxial compression kinematically equivalent to equi-biaxial stretching. As illustrated in Fig. 2, the critical stretch ratio of 1.26 was obtained by maximizing the voltage, which corresponds to a reduction in the thickness of 37\%. Generally, the electric field will become unstable when the stretch ratio is above this value and pull-in instability may be induced.

The output properties of DE actuators can be improved by mechanically inducing uniaxial or equi-biaxial pre-stretch which has a significant effect on the material's performance, including improving breakdown strength $[22,23]$ and reducing the effective compressive modulus which can enhance lateral actuation [14].

VHB 4910 is a polyacrylate, available as a commercial product from the 3 M Company. A VHB 4910 sample can exhibit a large deformation of about $100 \%$ [4] when a large voltage is applied. Kofod [23] proved that dielectric strength and electrostatic force were greatly increased by modelling cuboid DE actuators using VHB 4910 which has a relative permittivity of about 4.7. It was also found that the pull-in instability, which significantly affects the electrical performance of DEs, can be eliminated by applying a pre-stretch [24-27]. An investigation of the influence of pre-stretch on the electromechanical properties of DEs by

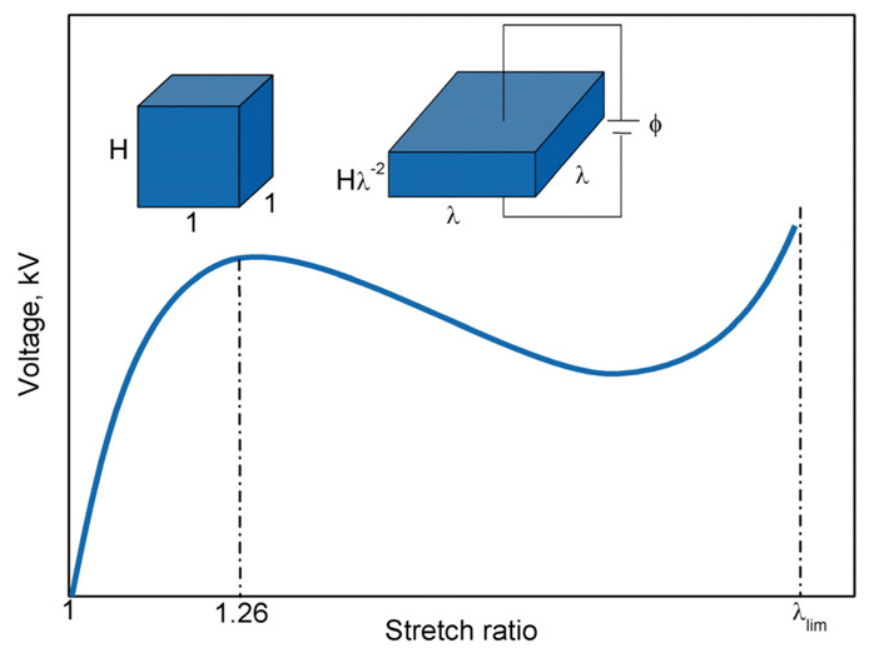

Fig. 2. A membrane of a dielectric elastomer subjected to a voltage reduces in thickness and expands in surface area. The voltage-stretch curve is typically not monotonic. using VHB 4910 and DEs based on silicone rubber containing $\mathrm{BaTiO}_{3}$ is presented here.

\section{Materials}

Two kinds of hyperelastic DE base materials were chosen for this research. A commercial silicone polymer, dimethylsiloxane (LSR 4305 DEV, Bluestar Ltd., U.S.A.), consisting of two parts (part A and part B) was used to fabricate DE samples and a commercial DE, VHB 4910, a polyacrylate from the UK $3 \mathrm{M}$ company, having a thickness of $1 \mathrm{~mm}$, was also employed. NYOGEL 756G (Nye Lubricants, Inc., USA) was chosen as the conductive carbon grease to be used as the compliant electrode for the DEs. $\mathrm{BaTiO}_{3}$ was chosen as the filler material and added to the silicone to improve its permittivity. The particle size of the filler was below $3 \mu \mathrm{m}$ and the density was $6.08 \mathrm{~g} / \mathrm{ml}$ at $25^{\circ} \mathrm{C}$ associated with a relative permittivity of 1200 at $1 \mathrm{kHz}$.

\section{Experimental}

\subsection{Sample preparation}

The silicone rubber used as the DE matrix contained two parts which were mixed at a ratio of $1: 1$. Barium titanate $\left(\mathrm{BaTiO}_{3}\right)$ was subsequently added to the silicone composite at a volume fraction of $10 \%$. The mixture was stirred manually for 10 minutes and then poured into two moulds for making samples about $0.3 \mathrm{~mm}$ in thickness for different uses: one for mechanical tests and one for dielectric and electromechanical tests. After degassing for 1.5 hours, the samples were solidified in a heating room at a temperature of $60{ }^{\circ} \mathrm{C}$ for 12 hours.

\subsection{Dielectric tests}

Wideband dielectric spectroscopy was carried out on samples at $20{ }^{\circ} \mathrm{C}$ in the frequency range from $0.1 \mathrm{~Hz}$ to $10 \mathrm{MHz}$ using a Turnkey broadband dielectric spectrometer. The cell used was a disposable gold-plated flat electrode with a diameter of $20 \mathrm{~mm}$ and thickness of $2 \mathrm{~mm}$. Samples were placed in the gap between the electrode and the sample holder.

\subsection{Electromechanical tests}

The electromechanical test system consisted of a camera, a biaxial clamp for pre-stretching and a high voltage power supply ranging from 0 to $10 \mathrm{kV}$. Samples of $0.3 \mathrm{~mm}$ thickness were coated on both faces with the compliant electrode. The samples were clamped at the edges to give various pre-stretch ratios. A camera recorded changes in the area of the compliant electrode when an electric field was incrementally applied in voltage steps of $0.5 \mathrm{kV}$. Triplicate samples were tested.

\section{Results and discussion}

\subsection{Dielectric tests}

Generally, dielectric constant increases with the enhancement of polarizability of molecules in materials. Polar groups are reoriented under the electric field to promote the elongation of molecular chains. Therefore, the voltage-induced deformation resulted from not only the external Maxwell stress but also the internal polarization of DEs.

Fig. 3 shows the plot of dielectric constant related with frequency for SR, SR with $10 \% \mathrm{BaTiO}_{3}$ and VHB 4910. The dielectric constant of VHB 4910 fell dramatically from approximately 4.9 to 3.5 at a frequency of $1 \mathrm{MHz}$ indicating that the polarization group had an obviously hysteretic response to the applied electric field. The dielectric constant of the silicone composite was measured at around 5 and changed only slightly 


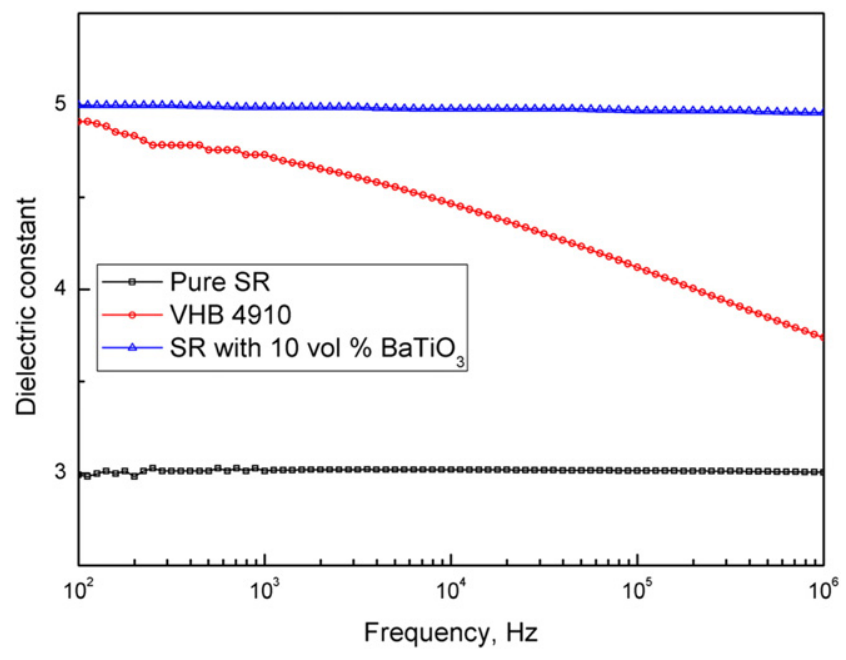

Fig. 3. Dielectric constant of silicone rubber, SR with $10 \% \mathrm{BaTiO}_{3}$ and $\mathrm{VHB} 4910$ dependent on frequency.

over the range of test frequencies. When compared, the permittivity of silicone rubber LSR $4305\left(\varepsilon^{\prime} \approx 2.9\right)$ was lower than that of VHB 4910. This was probably due to the larger polarity of the ester group in VHB 4910 by contrast with that of the non-polar structure of the molecule of silicone rubber. When the high dielectric particles $\mathrm{BaTiO}_{3}$ of $10 \mathrm{vol} \%$ were added in the silicone matrix, $\varepsilon^{\prime}$ increased to 5 and maintained this value in the wide frequency range from $100 \mathrm{~Hz}$ to $10 \mathrm{MHz}$. The appearance of dielectric enhancement is related to the Maxwell Wagner effect in the thin DE film [28]. This indicated that SR based DEs were more stable than VHB 4910 in respect of dielectric properties when subject to changes in frequency.

\subsection{Electromechanical tests}

The $3 \mathrm{~cm}$ square samples of silicone rubber with $10 \%$ barium titanate were stretched from their initial size in steps of $1 \mathrm{~cm}$ and to a final size of $6.5 \mathrm{~cm}$ square which was achieved just prior to tearing. The $2.5 \mathrm{~cm}$ square VHB 4910 samples were stretched, also in steps of $1 \mathrm{~cm}$, from their original size to a final size of $9.5 \mathrm{~cm} \times 9.5 \mathrm{~cm}$ before experiencing tear.

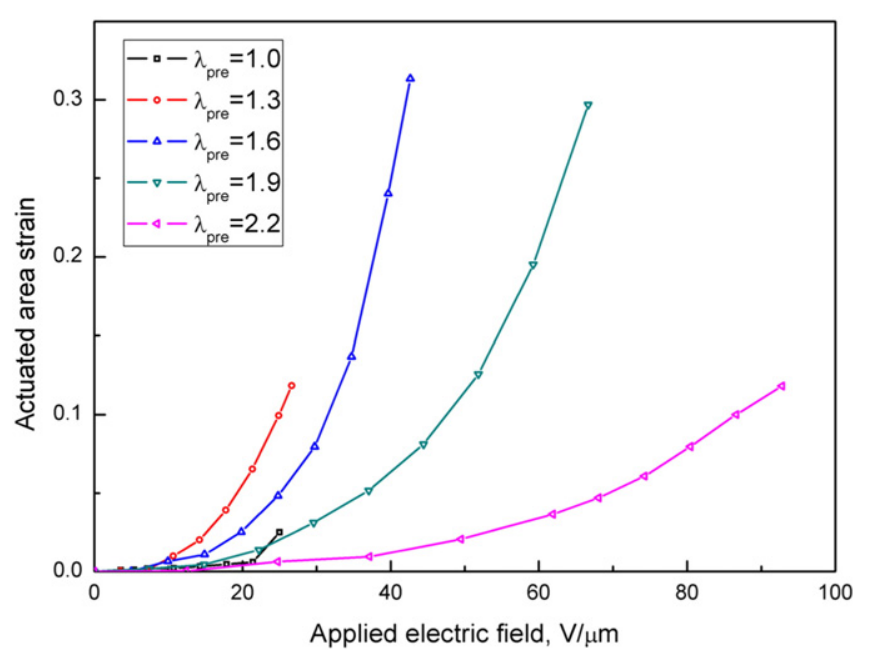

Fig. 4. Strain in area versus electric field applied to SR containing $10 \% \mathrm{BaTiO}_{3}$.
4.2.1. The behaviour of fabricated silicone rubber DEs with added $\mathrm{BaTiO}_{3}$ particles

Fig. 4 shows samples of fabricated DEs with increased deformations depending not only on the applied electric field but also on the prestretch ratio $\left(\lambda_{\text {pre }}\right)$. In the absence of a mechanical pre-stretch, small strains of no more than $0.3 \%$ were obtained; while pre-stretching the samples to a ratio of 1.6 achieved an increase in area of approximately $32 \%$. As can be observed from the plots, the voltage-induced area strain for each samples used in the experiment increased with the increase in electric field. However, the electric stimulus was negligible, below $10 \mathrm{~V} /$ $\mu \mathrm{m}$ and this was possibly because the input electrical energy was not enough to drive the molecular chains.

Fig. 5 shows changes in the area strain achieved by varying the prestretch ratio. For the fabricated DEs, the actuated area strain increased steadily for pre-stretch ratios up to $\lambda_{\text {pre }}=1.6$. After this threshold value, the area strain went down to $10 \%$ at a pre-stretch ratio of 2.2 . Thereafter, the samples fractured at higher pre-stretch ratios. Pre-stretching can induce the molecular chains to rearrange to have approximate linearity and thus promote larger strains, but there is a material dependent limit on the pre-stretch that induces maximum strain.

Pre-stretch has a beneficial effect on the enhancement of Dielectric strength $[29,30]$. Dielectric strength increased with increasing prestretch ratio, mainly due to a decrease in thickness. As can be seen from Fig. 6, dielectric strength changed little under an equi-biaxial pre-stretch ratio of 1.4, whereas the dielectric strength increased linearly up to $90 \mathrm{~V} / \mu \mathrm{m}$ beyond this ratio. As is well-known, polymer molecular chains are rearranged by the application of mechanical stress. Moreover, the mechanical stretch can generate free volume by driving the segmental motions of chains, which is propitious to increase the dielectric strength [31]. Furthermore, as a result of the thickness of the material being reduced when strained, the heat in DEs produced by the applied electric field can readily dissipate, which can also enhance dielectric strength [32].

The maximum pressure caused by the electrostatic force was calculated according to the dielectric strength and the relative permittivity of the composites. The maximum pressure increased to nearly $0.4 \mathrm{MPa}$ which was 10 times larger than the pressure produced without pre-stretch (refer to Fig. 7). Notably, pre-stretch can greatly influence the pressure produced in DE materials.

The elastic energy density $\left(e_{e}\right)$ is the amount of work generated in one actuation cycle per unit volume of the actuator. It is minimally affected by the compliant electrodes, power supplies, counter electrodes

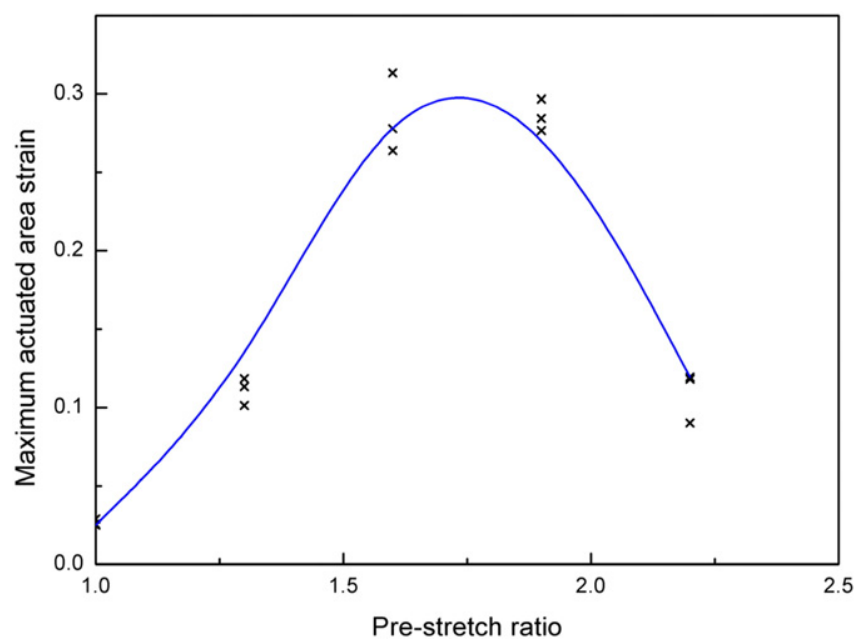

Fig. 5. Actuated area strain of SR with $10 \% \mathrm{BaTiO}_{3}$ at break related to equi-biaxial prestretch ratio. 


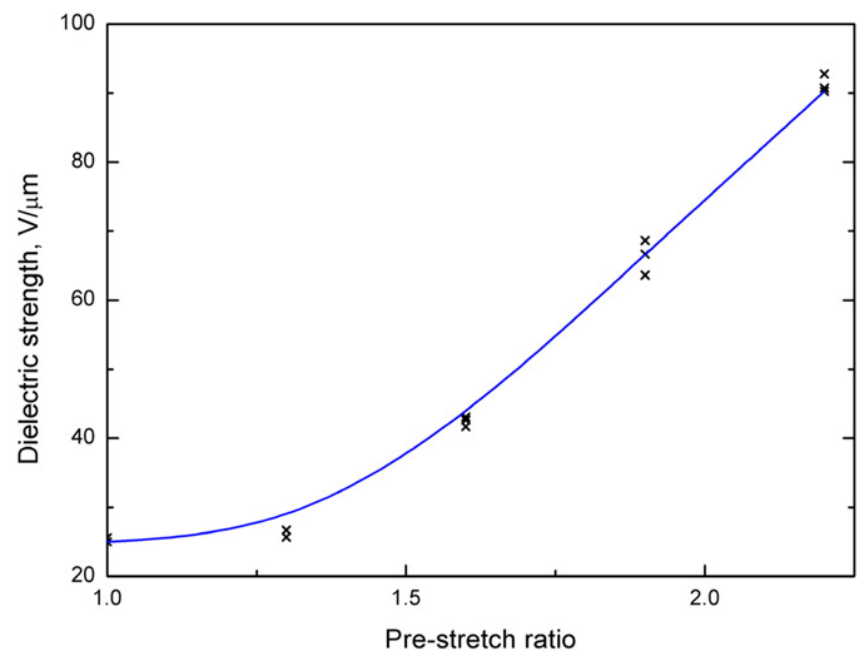

Fig. 6. Dielectric strength of SR with $10 \% \mathrm{BaTiO}_{3}$ at break, related to equi-biaxial prestretch ratio.

and packaging and can be calculated directly from experimentally measured quantities including the electrostatic stress and thickness strain. The equations representing these relations are as follows [33]:

If $\mathrm{s}_{\mathrm{z}}<10 \%, e_{e}=\mathrm{Ys}_{\mathrm{z}}^{2} / 2$

where $\mathrm{Y}$ is the modulus of elasticity for the DE material,

If $\mathrm{s}_{\mathrm{z}} \geq 10 \%, \quad e_{e}=-\mathrm{p} \ln \left(1-\mathrm{s}_{\mathrm{z}}\right)$.

The elastic energy density increased with increasing pre-stretch ratio. The maximum energy density achieved was $0.05 \mathrm{MJ} / \mathrm{m}^{3}$ (Fig. 8). However, the energy density appeared to decline for pre-stretching beyond ratios of about 2 .

As well as the elastic energy density, another important parameter for characterizing a DE's performance is the efficiency $\left(\mathrm{K}^{2}\right)$, which is the electrical energy, converted into mechanical work per cycle relative to the electrical energy applied per cycle. This can alternatively be thought of as the ratio of stored mechanical energy to input electrical energy. Presuming that the elastomers are virtually isochoric materials,

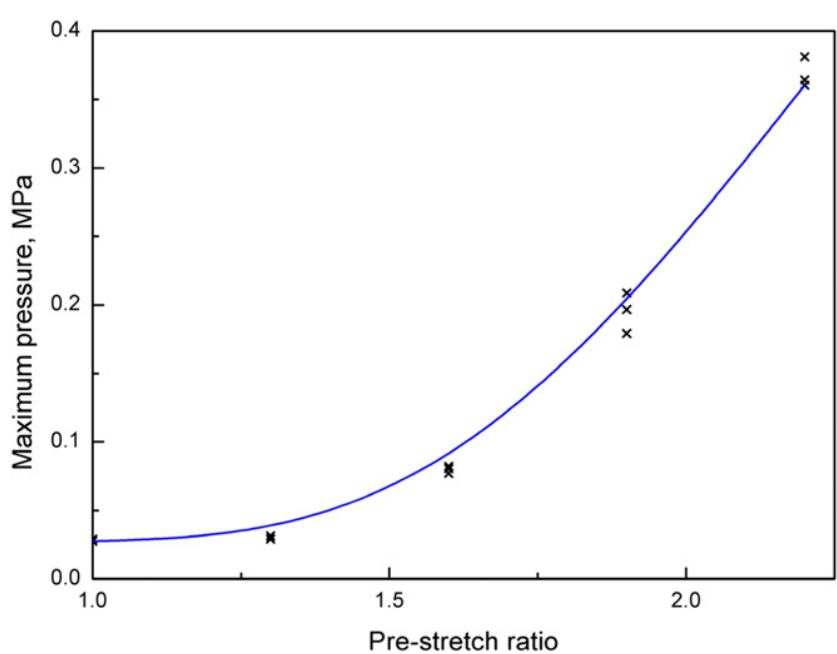

Fig. 7. Maximum pressure of $\mathrm{SR}$ with $10 \% \mathrm{BaTiO}_{3}$ related to equi-biaxial pre-stretch ratio

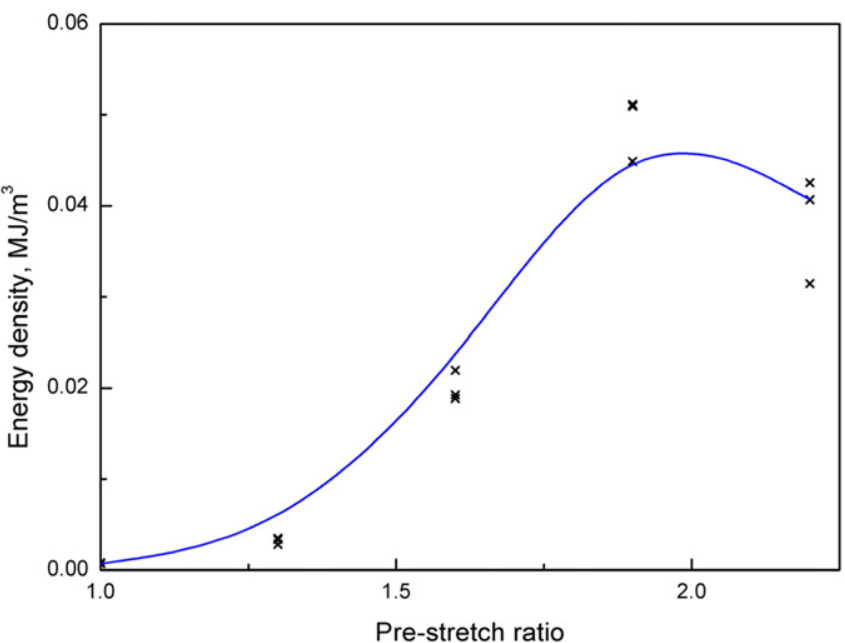

Fig. 8. Energy density of SR with $10 \% \mathrm{BaTiO}_{3}$ related to equi-biaxial pre-stretch ratio.

the change in electrical energy upon actuation is approximately equal to the work output; in which case $\mathrm{K}^{2}$ can be calculated using Eq. (5) [33]:

$\mathrm{K}^{2}=2 \mathrm{~s}_{\mathrm{z}}-\mathrm{s}_{\mathrm{z}}^{2}$.

The electromechanical coupling efficiency exhibited a parabolic distribution for pre-stretched samples. As can be observed in Fig. 9, the peak of the curve $(0.42)$ corresponded to a ratio somewhere between 1.6 and 1.9. The efficiency was directly dependent on the thickness strain induced by the electric field. $\mathrm{K}^{2}$ increased monotonically up to about 0.42 which corresponded to a deformation of $32 \%$ as can be seen from Fig. 5. It can be assumed that the maximum strain would be experienced at a ratio between 1.6 and 1.9.

\subsubsection{The influence of pre-stretch on electromechanical properties of $V H B$} 4910

Fig. 10 shows that VHB 4910 samples obtained a maximum actuated strain at breakdown of approximately $75 \%$ for an equi-biaxial prestretch ratio between $\lambda_{\text {pre }}=2.6$ and $\lambda_{\text {pre }}=3.0$. However, the change in shape of the samples was minimal in the absence of pre-stretch. At other values for pre-stretched samples, slight changes occurred when

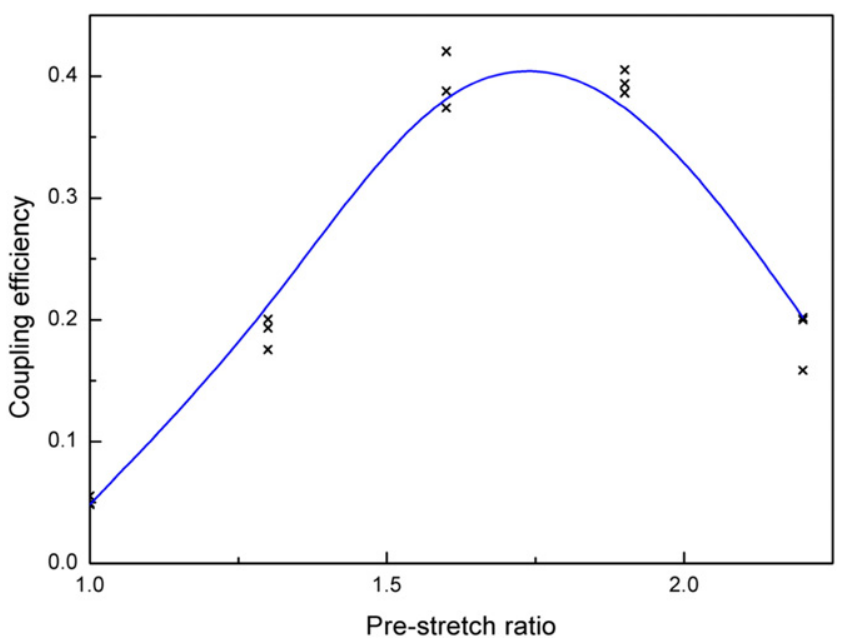

Fig. 9. Electromechanical coupling efficiency of SR with $10 \% \mathrm{BaTiO}_{3}$ related to equi-biaxial pre-stretch ratio. 




Fig. 10. Area strain versus electric field strength for VHB 4910.

applying electric fields under approximately $8 \mathrm{~V} / \mu \mathrm{m}$, while a steep increase occurred when the electric field was raised above this threshold value. However, as the transverse strain reached $37 \%$, corresponding to an area strain of $59 \%$, the films became wrinkled, indicating the onset of the pull-in effect in samples. As can be seen from Fig. 10, for the samples with pre-stretch ratios of 2.2, 2.8, 3.0 and 3.4, a plateau caused by the pull-in effect was reached before the samples punctured, while below the threshold, wrinkles were not found. The pull-in instability could be eliminated under these pre-stretch ratios for DEs if it was not essential to constrain DE test samples at their perimeters [24,34]. However, it should be considered that the maximum deformation of the samples was constrained by the frame employed in the test and this contributed to the pull-in instability in these experiments.

Pre-stretch plays an important part in electro-active deformation when applying high electric fields to DEs. Using this mechanical approach, the maximum actuated area strains at break were monotonically increased from almost zero without pre-stretch to $75 \%$ at stretch ratios of about 3. The area strain diminished to $34 \%$ at a pre-stretch ratio of 3.8 (Fig. 11). Considering that the molecular chains were completely extended when the DE samples were stretched nearly to tear, there was virtually no additional elongation stimulated by the application of an electric field.

Fig. 12 shows that dielectric strength can be enhanced by the equi-biaxial stretching of DE samples. The dielectric strength was

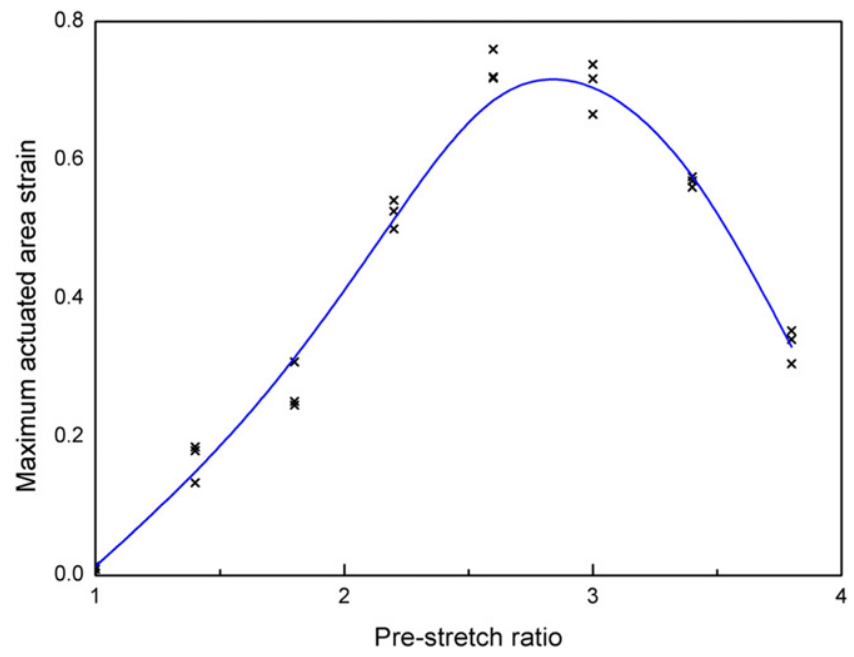

Fig. 11. The actuated area strain of VHB 4910 at break related to pre-stretch ratio.

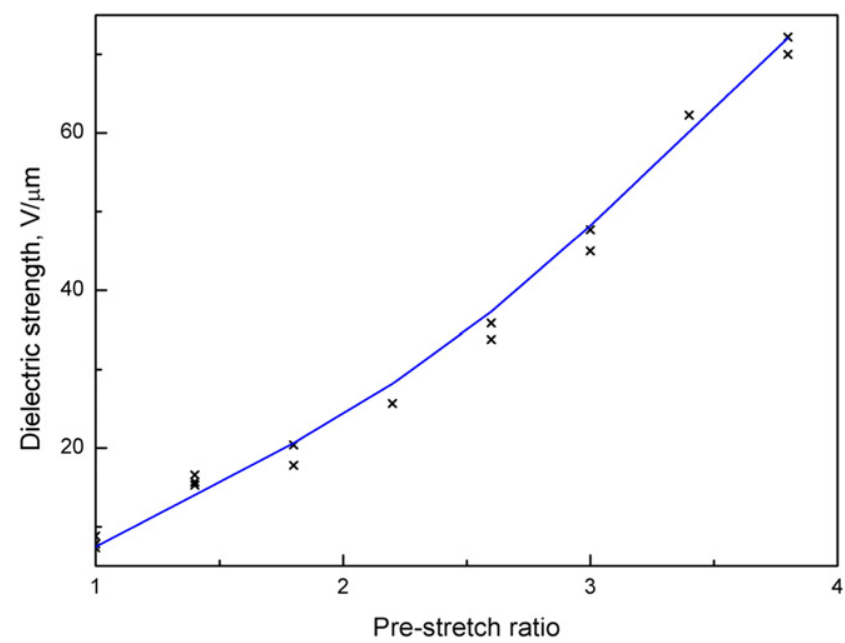

Fig. 12. Dielectric strength of VHB 4910 versus pre-stretch ratio.

above $70 \mathrm{~V} / \mu \mathrm{m}$ for VHB 4910 at the largest pre-stretch ratio of 3.8. This was because, firstly the pre-stretch reduced the thickness of the DE samples and secondly, pre-stretch promoted molecular alignment. However, the stretched samples suffered from relaxation in the elastomer and mechanical failure during the test process. This resulted in slight variations in electromechanical properties for all samples at different constant pre-stretch ratios.

An electrostatic pressure is created from the high electric field that is generated between the top and bottom surfaces of a DE material. Fig. 13 shows the relation between the electrostatic pressure and the equibiaxial pre-stretch ratio. Stress increased with increasing pre-stretch ratio and reached a maximum value above 0.16 at a pre-stretch ratio of 3.8. However, stress increased only slightly, by approximately $0.02 \mathrm{MPa}$, up to a ratio of 2.2 , before increasing markedly to a peak after this value.

The energy density $e_{e}$ increased dramatically from 0 to a maximum value of above $0.05 \mathrm{MJ} / \mathrm{m}^{3}$ (Fig. 14). $\mathrm{e}_{\mathrm{e}}$ mainly depends on the electrostatic force and the strain in the thickness direction. Below a stretch ratio of around 3.4, the electrostatic force contributed more to the energy density output than to the change in strain. Thereafter, the strain decreased as a result of the energy density reducing.

The relation between electromechanical coupling efficiency and equi-biaxial pre-stretch ratio was observed to be in the form of a parabolic curve (Fig. 15). As can be seen from the figure, a maximum value



Fig. 13. Maximum pressure of VHB 4910 versus pre-stretch ratio. 




Fig. 14. Energy density of VHB 4910 related to pre-stretch ratio.

of about $70 \%$ was achieved at a peak pre-stretch ratio between 2.6 and 3 . Also, $\mathrm{K}^{2}$ increased with increased actuated area strain at fracture in the range of 0 to $75 \%$. Hence, the form of the trend-line for $\mathrm{K}^{2}$ related to $\lambda_{\text {pre }}$ is similar to that for $s_{z}$ related to $\lambda_{\text {pre. }}$.

\section{Conclusions}

Pre-stretch greatly influences the electromechanical properties of DEs including those for DEs based on silicone and polyacrylate.

For silicone rubber based DEs with the inclusion of $\mathrm{BaTiO}_{3}$ particles, a maximum actuated area strain of $32 \%$ and maximum coupling efficiency of $42 \%$ were obtained for an equi-biaxial pre-stretch ratio of 1.6. The highest dielectric strength of $90 \mathrm{~V} / \mu \mathrm{m}$ and maximum pressure of about 0.4 MPa were each achieved for a DE with an equi-biaxial pre-stretch ratio of 2.2. The $\mathrm{DE}$ with an equi-biaxial pre-stretch ratio of 1.9 exhibited a maximum energy density of $0.05 \mathrm{MJ} / \mathrm{m}^{3}$.

For VHB 4910 samples, both the maximum strain in area of $75 \%$ and the maximum electromechanical coupling efficiency of $70 \%$ occurred at an equi-biaxial pre-stretch ratio of 3.0. The highest dielectric strength of $70 \mathrm{~V} / \mu \mathrm{m}$ and the maximum pressure of $0.16 \mathrm{MPa}$ were obtained by applying a driving voltage to the VHB 4910 at an equi-biaxial pre-stretch ratio of 3.8. A maximum energy density of $0.05 \mathrm{MJ} / \mathrm{m}^{3}$ was achieved for VHB 4910 at an equi-biaxial pre-stretch ratio of 3.4.

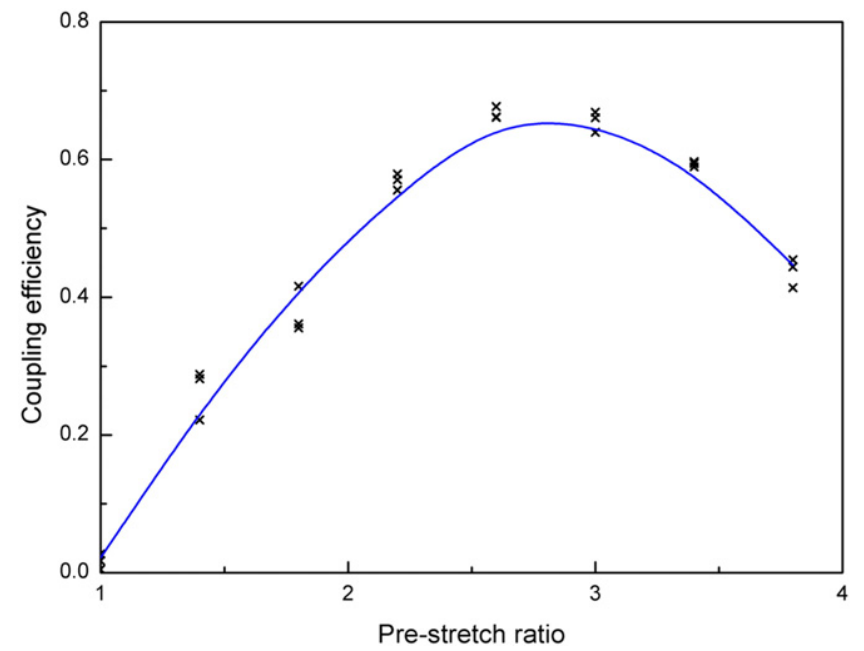

Fig. 15. Electromechanical coupling efficiency of VHB 4910 related to pre-stretch ratio.
Comparing the fabricated silicone DE with VHB 4910 showed that, though the maximum strain achieved for the silicone was slightly smaller, the maximum energy density output of each was roughly equal. Also, the maximum pressure and the maximum dielectric strength were much higher for the fabricated silicone DE samples containing $\mathrm{BaTiO}_{3}$ particles than for the commercially available VHB 4910 samples and importantly they did not exhibit a pronounced pull-in effect. However, both silicone and polyacrylate are considered promising materials for DE applications.

\section{Acknowledgement}

The authors would like to gratefully acknowledge the support from a DIT Fiosraigh Dean of Graduate Students Award.

\section{References}

[1] R.E. Pelrine, R.D. Kornbluh, J.P. Joseph, Electrostriction of polymer dielectrics with compliant electrodes as a means of actuation, Sensors Actuators A Phys. 64 (1998) 77-85.

[2] R. Pelrine, R.D. Kornbluh, O. Pei, S. Stanford, S. Oh, J. Eckerle, R.J. Full, M.A. Rosenthal, K. Meijer, Dielectric elastomer artificial muscle actuators: toward biomimetic motion, Proceeding of SPIE Electroactive Polymer Actuators and Devices, 2002, pp. $126-137$.

[3] C. Löwe, X. Zhang, G. Kovacs, Dielectric elastomers in actuator technology, Adv. Eng. Mater. 7 (2005) 361-367.

[4] R. Pelrine, R. Kornbluh, Q. Pei, J. Joseph, High-speed electrically actuated elastomers with strain greater than $100 \%$, Science 287 (2000) 836-839.

[5] K. Jung, K.J. Kim, H.R. Choi, A self-sensing dielectric elastomer actuator, Sensors Actuators A Phys. 143 (2008) 343-351.

[6] B. Choi, H.R. Choi, S. Kang, Development of tactile sensor for detecting contact force and slip, Proceeding of 2005 IEEE/RSJ International Conference Intelligent Robots and Systems, 2005, pp. 2638-2643.

[7] K. Ren, S. Liu, M. Lin, Y. Wang, Q.M. Zhang, A compact electroactive polymer actuator suitable for refreshable Braille display, Sensors Actuators A Phys. 143 (2008) 335-342.

[8] K. Gabor, L. Patrick, W. Michael, An arm wrestling robot driven by dielectric elastomer actuators, Smart Mater. Struct. 16 (2007) S306.

[9] Y. Luan, H. Wang, Y. Zhu, Design and implementation of cone dielectric elastomer actuator with double-slider mechanism, J. Bionic Eng. 7 (2010) S212-S217 (Supplement).

[10] R. Zhang, A. Kunz, P. Lochmatter, G. Kovacs, Dielectric elastomer spring roll actuators for a portable force feedback device, 14th Symposium on Haptic Interfaces for Virtual Environment and Teleoperator Systems, Part of IEEE Virtual Reality 2006, 2006, pp. 25-26.

[11] C. Federico, S. Claudio, R. Danilo De, Folded dielectric elastomer actuators, Smart Mater. Struct. 16 (2007) S300.

[12] S. Michel, A. Bormann, C. Jordi, E. Fink, Feasibility studies for a bionic propulsion system of a blimp based on dielectric elastomers, Proceeding of SPIE Electroactive Polymer Actuators and Devices, 2008, p. 69270S.

[13] S. Chiba, M. Waki, R. Kornbluh, R. Pelrine, Innovative power generators for energy harvesting using electroactive polymer artificial muscles, Proceeding of SPIE Electroactive Polymer Actuators and Devices, 2008, pp. 692715-692719.

[14] S. Chiba, M. Waki, R. Kornbluh, R. Pelrine, Current status and future prospects of power generators using dielectric elastomers, Smart Mater. Struct. 20 (2011) 124006.

[15] E. Dimopoulos, I. Trintis, S. Munk-Nielsen, Comparison of the dielectric electroactive polymer generator energy harvesting cycles, Proceeding of SPIE Electroactive Polymer Actuators and Devices, 2013, p. 868700 (13).

[16] C. Jean-Mistral, T. Vu-Cong, A. Sylvestre, On the power management and electret hybridization of dielectric elastomer generators, Smart Mater. Struct. 22 (2013) 104017-104029.

[17] X. Zhao, W. Hong, Z. Suo, Electromechanical hysteresis and coexistent states in dielectric elastomers, Phys. Rev. B 76 (2007) 134113.

[18] T. McKay, B. Obrien, E. Calius, I. Anderson, An integrated, self-priming dielectric elastomer generator, Appl. Phys. Lett. 97 (2010) 062911-062912.

[19] G. Gallone, F. Carpi, D. De Rossi, G. Levita, A. Marchetti, Dielectric constant enhancement in a silicone elastomer filled with lead magnesium niobate-lead titanate, Mater. Sci. Eng. C 27 (2007) 110-116.

[20] J. Qiang, H. Chen, B. Li, Experimental study on the dielectric properties of polyacrylate dielectric elastomer, Smart Mater. Struct. 21 (2012) 025006.

[21] Z. Suo, Theory of dielectric elastomers, Acta Mech. Solida Sin. 23 (2010) 549-578.

[22] G. Kofod, P. Sommer-Larsen, R. Kornbluh, R. Pelrine, Actuation response of polyacrylate dielectric elastomers, J. Intell. Mater. Syst. Struct. 14 (2003) 787-793.

[23] G. Kofod, The static actuation of dielectric elastomer actuators: how does pre-stretch improve actuation? J. Phys. D. Appl. Phys. 41 (2008) 215405.

[24] X. Zhao, Z. Suo, Theory of dielectric elastomers capable of giant deformation of actuation, Phys. Rev. Lett. 104 (2010) 178302.

[25] B. Li, H. Chen, J. Qiang, S. Hu, Z. Zhu, Y. Wang, Effect of mechanical pre-stretch on the stabilization of dielectric elastomer actuation, J. Phys. D. Appl. Phys. 44 (2011) 155301. 
[26] T. Lu, J. Huang, C. Jordi, G. Kovacs, R. Huang, D.R. Clarke, Z. Suo, Dielectric elastomer actuators under equal-biaxial forces, uniaxial forces, and uniaxial constraint of stiff fibers, Soft Matter 8 (2012) 6167-6173.

[27] C. Keplinger, T. Li, R. Baumgartner, Z. Suo, S. Bauer, Harnessing snap-through instability in soft dielectrics to achieve giant voltage-triggered deformation, Soft Matter 8 (2012) 285-288.

[28] M. Shen, S. Ge, W. Cao, Dielectric enhancement and Maxwell-Wagner effects in polycrystalline ferroelectric multilayered thin films, J. Phys. D. Appl. Phys. 34 (2001) 2935.

[29] P.H.F. Morshuis, Degradation of solid dielectrics due to internal partial discharge: some thoughts on progress made and where to go now, IEEE Trans. Dielectr. Electr. Insul. 12 (2005) 905-913.
[30] Z. Xin, X. Zhao, Z. Suo, Z. Chen, J. Runt, S. Liu, Z. Shihai, Q.M. Zhang, Electrical breakdown and ultrahigh electrical energy density in poly(vinylidene fluoridehexafluoropropylene) copolymer, Appl. Phys. Lett. 94 (2009) 162901-162903.

[31] L.A. Dissado, J.C. Fothergill, Electrical Degradation and Breakdown in Polymers, Peter Peregrinus Ltd., 1992

[32] C. Wadhwa, High Voltage Engineering, New Age International, 2007. 30-38.

[33] R. Shankar, T.K. Ghosh, R.J. Spontak, Dielectric elastomers as next-generation polymeric actuators, Soft Matter 3 (2007) 1116-1129.

[34] X. Zhao, Z. Suo, Method to analyze electromechanical stability of dielectric elastomers, Appl. Phys. Lett. 91 (2007) 061921. 